\title{
A influência das motivações sobre a vontade na filosofia moral de Immanuel Kant
}

\section{The influence of motivations on will in Immanuel Kant's moral philosophy}

\author{
RODRIGO LOPES FIGUEIREDO ${ }^{1}$
}

\begin{abstract}
Resumo: As motivações que influenciam a vontade humana, submetida às condições advindas da sensibilidade é o foco de nossa pesquisa. A questão que nos interpela neste sentido é a seguinte: como é possível viver exclusivamente segundo móbiles, ignorando (deliberadamente) os princípios "a priori" de determinação da moralidade? Nosso objetivo geral consiste, portanto, em entender porque Kant desqualifica todo e qualquer objeto sensível e condição subjetiva e/ou objetiva relativa à experiência, quando estes influenciam a vontade do sujeito moral e o objetivo específico. Trata-se, ainda, de compreender em que medida o querer racional, quando misturado aos móbiles, constitui uma vontade incapaz de reconhecer dignidade em si e nos outros.
\end{abstract}

Palavras-chave: Motivação. Vontade. Condição. Felicidade. Lei moral.

Abstract: The motivations that influence the human will, submitted to the conditions coming from the sensibility is the focus of our research. The question that challenges us in this sense is: how is it possible to live exclusively by mobiles, ignoring (deliberately) the "a priori" principles of determination of morality? Our general objective, therefore, is to understand why Kant disqualifies any and all subjective objects and subjective and / or objective conditions relative to experience when they influence the will of the moral subject and the specific objective. It is also a question of understanding to what extent the rational will, when mixed with the mobiles, constitutes a will incapable of recognizing dignity in itself and in others.

Keywords: Motivation. Will. Condition. Happiness. Moral law.

\section{Kant e a influência das motivações sobre a vontade na filosofia moral}

O presente trabalho é uma partilha de estudos sobre o papel das inclinações naturais na filosofia moral de Immanuel Kant, tendo em vista a redação do primeiro capítulo de minha dissertação intitulado "Das motivações determinantes do agir moral em Kant". Nossa reflexão parte das obras "Fundamentação da metafísica dos costumes" (1785) e "A religião nos limites da simples razão" (1793) escoltadas pelas demais publicações presentes nas referências situadas ao final.

Antes de iniciarmos nossa reflexão sobre o problema em questão é pertinente dizer que, segundo Kant, a sensibilidade (faculdade humana que dá suporte de apreensão e expressão das qualidades sensíveis) é entendida numa espécie de passividade, cuja função é captar os fenômenos com que nos deparamos; já a razão tem um caráter operante, cuja natureza determina o que pode acontecer em sentido prático. Tal distinção não visa apresentar uma visão dicotômica de tais faculdades,

\footnotetext{
${ }^{1}$ Acadêmico do Programa de Pós-Graduação Stricto sensu (Mestrado em Filosofia da UNIOESTE). Email: digofilo@gmail.com.
} 
mas as considera complementares, sobretudo quando refletimos sobre a dimensão prática, onde se manifesta a nossa vontade.

Considerando as ações humanas na condição submetida à sensibilidade não desprezamos a relevância operativa da razão; ao contrário, queremos entender como se constituí toda determinação "a priori" quando pretende abstrair dos conteúdos sensíveis, verificando por que tais qualidades não podem constituir-se princípio de determinação moral. Tal assunto é de grande importância em nossos dias, visto que, vê-se por toda parte ações e mais ações realizadas por deliberado interesse, por inclinação imediata ou motivada por algum instinto cujo alvo é o bem-estar e a felicidade.

Conforme nos instrui o próprio Kant em sua obra Fundamentação da metafísica dos costumes (2009, p.197-199), consideramos a sua abordagem prática sob dois aspectos: o primeiro refere-se a designação "condicionado", onde se encontram as ações e comportamentos realizados sob condições escolhidas segundo o 'destino' do bem estar e no interesse da felicidade e o segundo remete ao “incondicionado" - âmbito permeado pelo respeito à lei moral, onde a vontade humana escolhe agir por dever, guiada por princípios "a priori" representados na razão.

O foco de nosso estudo reside em especial no âmbito "condicionado" onde se realizam as escolhas provenientes da racionalidade prático-instrumental, cuja intenção é dirigida pelos imperativos hipotéticos; ou seja, pelas regras de habilidade que determinam a vontade humana segundo uma lógica de "custo-benefício" submetido à inteligência; neste sentido são pensados os meios mais adequados em vista dos fins visados. A manifestação de tais ditames racionais verifica-se nas ações realizadas em vista do bem estar imediato e da felicidade, cujos meios possíveis residem no "cálculo prudente" e interessado de alguém que se volta a uma determinada situação (que pode lhe ser favorável ou não) prevendo as possíveis consequências antes mesmo de acontecer ou no momento em que age. Daí a designação 'condicionado' - cujo significado revela a operação do arbítrio consciente das condições empíricas e que pode realizar comandos tendo em vista os seus interesses ou os interesses de quem lhe aprouver. Kant evidencia o caráter relativo, contingente e subjetivo desta 'modalidade voluntária', denotando grande preocupação pelo fato de haver se tornado tão frequente em sua época o aspecto utilitarista da ação.

No limiar de nossas reflexões está a vontade humana, permeada por influências de toda ordem: instintos, interesses, emoções, sentimentos, ideias, máximas, regras, a lei moral, etc. Contudo, é no arbítrio humano que ocorre a efetivação do fator que leva a decisão. Vejamos o que nos diz Kant a respeito: 
[...] A liberdade do arbítrio tem a qualidade inteiramente peculiar de ele não poder ser determinado a uma acção por móbil algum $a$ não ser apenas enquanto o homem o admitiu na sua máxima (o transformou para si em regra universal de acordo com o qual se quer comportar); só assim é que um móbil, seja ele qual for, pode subsistir juntamente com a absoluta espontaneidade do arbítrio (a liberdade) (KANT, 1992, p. 29-30).

Como vemos, por mais conturbadas que sejam as condições empíricas ou as circunstâncias a nossa volta, a influência ou afetação de algum móbil sobre nós ocorre somente devido a decisão livre de nosso arbítrio quando consentimos racionalmente, acolhendo a sua 'influência sensível'.

O que seria o 'móbil' e qual a sua influência sobre a vontade?

O móbil seria aquilo que move a vontade no sentido da realizar escolhas, em resumo seriam: os afetos, paixões, sentimentos, as inclinações em geral. É importante ressaltar que embora movam a vontade, motivando-a, não significa que sejam 'em si' determinantes do que irá acontecer.

A fim de entender melhor sobre a influência dos móbiles vejamos o estudo de Kant acerca da disposição ou indisposição voluntária. Em sua obra $A$ religião nos limites da simples razão, o pensador alemão distingue três espécies de disposições relativas à vontade: $\mathbf{1}^{\mathbf{0}}$ ) disposição para a animalidade, $2^{2}$ ) disposição para a humanidade e $3^{\mathbf{0}}$ ) disposição para a personalidade. Para efeito do presente trabalho analisaremos pontualmente a segunda disposição da vontade. $\mathbf{1}^{\circ}$ ) Disposição para a animalidade - refere-se ao 'mecanismo instintivo' de autoconservação, presente em nossa natureza irracional, enquanto necessidade absolutamente básica, onde não há livre espontaneidade, apenas reações inatas associadas a conservação orgânica. Em resumo: Kant denomina tais motivações de "arbítrio animal" (arbitrium brutum) (cf KANT, 2008, p. 42), onde, a exemplo dos animais, temos impulsos e desejos irracionais que vem à tona devido a nossa constituição orgânica destinada ao cumprimento de fins naturais. Lembremos aqui da noção de physis pensada entre os filósofos pré-socráticos enquanto sentido ou ordem 'in natura' independente da vontade humana.

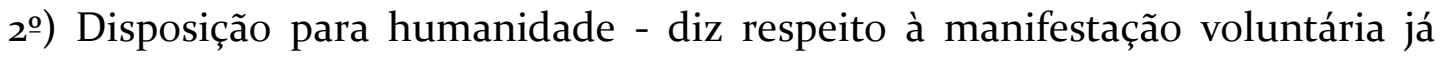
guiada pela inteligência racional, cuja direção ainda segue o curso das motivações empíricas livres em vista do bem estar imediato (diante dos outros); vê-se aqui uma espécie de atitude calculada em vista de si mesmo, cuja motivação é o "amor de si"; aqui verifica-se a manifestação da inveja, do ciúme, do ressentimento, do sentimento de vingança, da ambição entre outros impulsos egoístas constituídos numa 'atmosfera' de competição valorativa. Vejamos o que nos diz Kant (1992, p. 33:

Do amor de si promana a inclinação para obter para si um valor na opinião dos outros; e originalmente, claro está, apenas o da 
igualdade: não conceder a ninguém a superioridade sobre si, juntamente com um constante receio de que os outros possam a tal aspirar; daí surge um desejo injusto de adquirir para si essa superioridade sobre outros. - Aqui, a saber, na inveja e na rivalidade podem implantar-se os maiores vícios de hostilidades secretas ou abertas contra todos os que para nós consideramos estranhos, vícios que, no entanto, não despontam por si mesmos da natureza como de sua raiz, mas, na competição apreensiva de outros em vista de uma superioridade que nos é odiosa, são inclinações para alguém, por mor da segurança, a si mesmo a proporcionar sobre os outros, como meio de precaução: já que a natureza só queria utilizar a ideia de semelhante emulação (que em si não exclui o amor recíproco) como móbil para a cultura.

Em outra passagem desta mesma obra Kant reforça a afirmação acima mostrando a influência prejudicial dos móbiles sobre a vontade, potencializada quando recebemos a influência de outros que se comprazem na prática da imoralidade e da maldade.

[...] A inveja, a ânsia de domínio, a avareza e as inclinações hostis a elas associadas assaltam a sua natureza, em si moderada, logo que se encontra no meio dos homens, e nem sequer é necessário pressupor que estes já estão mergulhados no mal e constituem exemplos sedutores; basta que estejam aí, que o rodeiem, e que sejam homens, para mutuamente se corromperem na sua disposição moral e se fazerem maus uns aos outros. (KANT, 1992, p. 100).

A natureza humana subjetiva 'em si' não é corrompida; ou seja, desviante da lei moral, pois quando agimos buscamos suprir as necessidades de conservação naturais no sentido da sobrevivência; a questão surge quando estamos diante dos outros em sociedade e somos valorados ou considerados em função de nossa condição empírica, aí somos cobrados segundo padrões relativos, considerando-se o grau de estudo, a classe social, a nossa etnia, a religião, etc. a que pertencemos. Contudo, aí ainda não reside o pior, o problema maior ocorre quando permitimos relativizar as situações 'a meu favor' arrogando-nos de nossa condição empírica para daí extrair algum valor no interesse de não ser desprezado (a) pelos outros ou de obter algum benefício ou vantagem para si e para os familiares. Em resumo: corremos o risco de mergulharmos num convencionalismo, esquecendo-nos dos princípios dirigentes da moralidade, relativizando o respeito à lei moral, desviando por completo do que determina a 'urgência necessária e universal' do incondicionado presente dentro de nós.

A boa vontade presente na Fundamentação da metafísica dos costumes jamais pode ser contingente, ou seja, refém de alguma condição exigida para a sua manifestação, caso contrário ela pode tornar-se interesseira e utilitarista; por isso Kant inicia a primeira seção desta obra mostrando a vontade moral enquanto irrestritamente boa, ou seja, aquela que não está submetida a condição, restrição ou 
elemento efêmero, constituindo-se no caráter, cujas funções seriam: 1o $)$ corrigir a soberba, $\mathbf{2}^{\mathbf{o}}$ ) dirigir o querer relativo conformando-o a princípios universais e $3^{\mathbf{o}}$ ) restringir o amor próprio, impedindo que esteja submetido às paixões. Neste sentido, vê-se que entre os interlocutores de Kant nos debates filosóficos ocorridos na modernidade está o pensador britânico Jeremy Bentham, filósofo pertencente ao utilitarismo ético, cujo objetivo era pensar sobre as ações que promovem o bemestar e a felicidade ao maior número possível de pessoas.

Embora admita que a felicidade é uma 'ocorrência insolúvel' (Fundamentação,2009; p.205) devido ao fato de não termos certeza de quais condições empíricas nos mantém num estado de fruição feliz, numa constância temporal, recaindo em aspectos por demais subjetivos e empíricos, Kant reflete sobre os objetos sobre os quais se dirige a inclinação e os interesses humanos, daí nasce a heteronomia da vontade; ou seja, a determinação voluntária submetida a fatores externos ao próprio agente moral, mas que 'em si' não permitem-lhe uma autonomia ética da vontade.

Na primeira parte da Crítica da razão prática (1788) apresenta-se um estudo sobre a relação entre o sujeito e o objeto, considerando as motivações envolvidas no processo de interação relacional: "Todos os princípios práticos, que pressupõe um objeto (matéria) da faculdade de apetição como fundamento determinante da vontade, são no seu conjunto empíricos e não podem fornecer nenhuma lei prática" (KANT, 2008.I, p. 36) e acrescenta:

Todos os princípios práticos materiais são, enquanto tais, no seu conjunto de uma e mesma espécie e incluem-se no princípio geral do amor de si ou da felicidade própria. O prazer decorrente da representação da existência de uma coisa, na medida em que deve ser um fundamento determinante do apetite por essa coisa, fundase sobre a receptividade do sujeito, porque ele depende da existência de um objeto; por conseguinte ele pertence ao sentido (sentimento) e não ao entendimento, que expressa uma referência da representação a um objeto segundo conceitos, mas não ao sujeito segundo sentimentos. Portanto, ele é prático somente na medida em que a sensação de agrado que o sujeito espera da efetividade do objeto determina a faculdade de apetição. Ora a consciência que um ente racional tem do agrado da vida e que acompanha ininterruptamente toda a sua existência é, porém, a felicidade; e o princípio de tornar esta o fundamento determinante supremo do arbítrio é o princípio do amor de si (KANT, 2008.II, p. 37-38).

Como vemos, a condição de receptividade do sujeito em relação ao objeto do seu querer desejante constitui uma espécie de campo relacional cujas escolhas giram em torno de uma busca constante de benefícios, compensações e retribuições visadas. Quanto mais experientes quanto a vivência de algumas situações empíricas, tão mais aprimorados nos tornamos na busca prudente e eficiente do prazer e da 
satisfação, os quais convergem numa intenção de que estamos gozando da felicidade. Este processo relacional entre sujeito desejante e objeto desejado pode acontecer subjetiva ou intersubjetivamente, visto que, a exemplo do que nos ensina o filósofo inglês Jeremy Bentham podemos compartilhar a busca do prazer e a fuga da dor e do prejuízo tendo em vista o princípio da utilidade pública:

A natureza colocou o gênero humano sob o domínio de dois senhores soberanos: a dor e o prazer. Somente a eles compete apontar o que devemos fazer, bem como determinar o que na realidade faremos. Ao trono desses dois senhores está vinculada, por minha parte, a norma que distingue o que é reto do que é errado, e, por outra, a cadeia das causas e dos efeitos. Os dois senhores de que falamos nos governam em tudo o que fazemos, em tudo o que dizemos, em tudo o que pensamos, sendo que qualquer tentativa que façamos para sacudir este senhorio outra coisa não faz senão demonstrá-lo e confirmá-lo. [...] O princípio da utilidade reconhece tal sujeição e a coloca como fundamento desse sistema, cujo objetivo consiste em construir o edifício da felicidade através da razão e da lei. [...] Por princípio de utilidade entende-se aquele princípio que aprova ou desaprova qualquer ação, segundo a tendência que tem a aumentar ou a diminuir a felicidade da pessoa cujo interesse está em jogo. (BENTHAM. 1979, p.3-4).

Fazendo um paralelo entre os trechos de ambos os pensadores entende-se que:

a) A felicidade é uma referência motivadora das escolhas humanas;

b) O desejo de ser feliz é um caractere inato pertencente a nossa constituição natural;

c) Todos estamos sob a influência do ideal "ser feliz".

Agora analisemos as perspectivas de ambos os filósofos em separado.

Vejamos primeiramente a proposta do utilitarismo a partir do próprio Jeremy Bentham:

Ao considerar a dor e o prazer elementos radicados em nossa constituição natural, Bentham nos mostra que a ordem utilitária está presente em todos nós, independente de agirmos "por si" (pensando e agindo a 'meu favor') ou pelos outros, pertencendo a alguma entidade social ou política, cujas necessidades são públicas. Deste modo as necessidades cotidianas permitiriam a elevação da ação e da atitude pessoal a um patamar de exigência que visa resultados manifestos. Neste sentido são relevantes também os costumes, os conselhos, as regras de conduta, as habilidades postas à prova, as instituições constituídas e a tradição cultural herdada; todos fatores empíricos emergentes como fruto das vicissitudes cotidianas.

Bentham despreza as formulações teóricas, os princípios e até mesmo as leis que não tenham correspondente objetivo na realidade empírica e mais, que não 
sejam úteis a ponto de levar "algo a funcionar" segundo o curso do seu destino natural ou segundo os propósitos projetados pelo artifício humano. Na condução das decisões está a vontade, cuja finalidade última é a felicidade, entendida segundo uma "lógica" de cálculo inteligente onde a necessidade do bem estar individual convergiria para a satisfação pública e vice-versa.

Por fim, entende-se a proposta do pensador inglês como um sistema cujos meios são escolhidos em função do fim visado - a felicidade.

Retornemos a consideração kantiana em relação à felicidade:

Kant não nega o valor teleológico da felicidade quando esta constituí o bem motivacional da vontade não contrário a lei moral, somente nos alerta para o caráter objetual a que estamos inclinados a incorrer, visto sermos seres sensíveis cuja inteligência se volta constantemente a resolução de questões práticas do cotidiano, onde, por motivos de utilidade, tendemos a realizar escolhas cujos objetos do interesse resolvam os nossos problemas de modo menos penoso e desgastante e mais aprazível e auto protetivo.

O problema está em considerar a felicidade 'fundamento determinante supremo do arbítrio', pois aí cada qual considera o que lhe é mais conveniente para usufruto prático e a experiência dirigida por alguém cuja vontade é tão prática que chega a ignorar os princípios "a priori" do dever se torna objetualizante, colocando o próprio sujeito dotado de liberdade numa condição de objeto. Na ilusão de estar fazendo bem a si mesmo o sujeito racional calcula as máximas (como meios) subordinando-as a inclinação dirigida ao objeto visado pelo desejo.

Vejamos o que nos diz Kant sobre o 'princípio do amor de si':

Finalmente, o egoísta moral é aquele que reduz todos os fins a si mesmo, que não vê utilidade senão naquilo que lhe serve, e também como eudemonista coloca simplesmente na utilidade e na própria felicidade, e não na representação do dever, o fundamento-dedeterminação supremo de sua vontade. Pois como cada ser humano forma conceitos diferentes sobre aquilo que considera fazer parte da felicidade, é precisamente o egoísmo que leva a não ter pedra de toque alguma do genuíno conceito do dever, que, como tal, tem de ser inteiramente um princípio de validade universal. - Todos os eudemonistas são, por isso, egoístas práticos. (KANT, 2006, §2, p. 29-30).

Os 'eudemonistas' são aqueles que pensam a ação e o comportamento moral dirigido a felicidade como fim em si mesma; Kant afirma que, independente dos fins agradáveis e aprazíveis decorrentes de algum “objeto empírico" a ação por dever é necessária e, manifestando-se segundo princípios incondicionados rompe com o sentido utilitarista esperado por todos aqueles cuja conduta está mergulhada na instrumentalidade interesseira. 
Aqueles que assumem o princípio benthaniano da utilidade, entendendo a felicidade (governada pela dor e pelo prazer) como sentido exclusivo de suas vidas, seriam capazes de reprovar até mesmo uma atitude moralmente admirável do ponto de vista ético, caso não fosse pertinente ou eficiente no que se refere ao ideal de felicidade; seria, vamos dizer, uma atitude inconveniente, por estar 'fora do jogo' dos interesses.

Outro aspecto importante a ressaltar é quanto à pseudo pretensão de controle dos 'objetos aprazíveis' úteis ao sentido da felicidade, cujas escolhas livres estariam numa espécie de "saber é poder" frente às condições empíricas. Vejamos o exemplo hipotético de uma criança que, no interior do supermercado, manifesta o interesse de ganhar aquele brinquedo negado pelos pais; vendo seu desejo frustrado, se joga no chão, grita e esperneia com o objetivo de controlar afetivamente a situação a seu favor; envergonhados, os pais permanecem firmes no propósito de não comprar o brinquedo dirigindo-se ao caixa para finalizar a compra.

A situação acima demonstra que nem sempre as condições estão a 'nosso favor', nem sempre acontece aquilo que quero, nem sempre concordam comigo e contigo e, temos de admitir: nem sempre as outras pessoas estão dispostas a admitir a utilidade daquilo que considero importante. E daí o que vamos fazer? Espernear como a criança? Tentar controlar a situação criando mecanismos de persuasão dos outros a fim de 'estarem do nosso lado'?

No trecho acima citado, onde Kant se refere ao egoísmo prático, percebemos os limites objetuais a que nos destinamos quando pautamos a nossa vida exclusivamente segundo o princípio da utilidade defendido por Bentham. Contudo, há ainda que se investigar a aplicação deste princípio numa escala pública, verificando as possíveis consequências.

Como seria uma sociedade utilitarista? Ela seria baseada em condições materiais e em ações e comportamentos humanos, objetivamente manifestos e possivelmente administrados. Seria pautada na busca imediata do prazer e nos resultados bons para todos. Seria pautada na fuga da dor (física, moral e psicológica) e na previsão de evitá-la a qualquer custo. Reconheceria os feitos humanos considerados úteis, rejeitando os considerados inúteis. Seria promotora dos que sabem 'jogar bem o jogo' das regras sociais e do sistema, contudo minimizando o valor dos que não 'sabem jogar' ou daqueles que se recusam a 'jogar'.

Em resumo: tal sociedade seria pautada numa lógica de custo-benefício que beira ao narcisismo social, visto que se aceita somente os objetos, ambientes, pessoas e demais seres vivos que são pertinentes à intencionalidade do útil; algo que representaria uma ameaça real ao contexto político democrático.

É pertinente ressaltar também que, a utilidade não pode ser acolhida como princípio (exclusivo) dirigente do arbítrio, mesmo quando remete aquilo que é útil a 
todos, pois o caráter fundante da utilidade recaí num relativismo moral repleto de princípios úteis aqueles que fazem parte do "campo relacional”, mas quando se está em outro "campo relacional" aquilo que é útil muda, exigindo que se escolha o que é útil naquela concepção de felicidade.

Sabendo da ocorrência do princípio utilitarista na contingência empírica, Kant considera o primeiro nível das decisões humanas sob a direção dos imperativos hipotéticos, cujo sentido está voltado à busca da felicidade.

\begin{abstract}
Há, não obstante, um fim que se pode pressupor como efetivamente real em todos os seres racionais (na medida em que a eles convêm imperativos, a saber, enquanto seres dependentes), logo uma intenção que eles não somente podem ter, mas da qual se pode pressupor com segurança que todos têm segundo uma necessidade natural, e tal é a intenção da felicidade. O imperativo hipotético que representa a necessidade prática da ação como meio para a promoção da felicidade é assertórico. Não se deve apresentá-lo simplesmente como necessário para uma intenção incerta, meramente possível, mas, sim, <como necessário> para uma intenção que se pode pressupor com segurança e a priori em todo homem. Porque pertence à sua essência. Ora, pode-se chamar à habilidade na escolha dos meios para o seu máximo bem-estar próprio prudência no sentido mais estreito. (KANT. 2009, p. 195).
\end{abstract}

As molas propulsoras dos imperativos hipotéticos são o bem-estar e a satisfação, constituindo-se em geral uma certa previsão dos meios pertinentes a obtenção do que se quer. Neste sentido, conselhos de pessoas mais experientes podem ser importantes, exemplos ou o testemunho de alguém que passou por determinada situação e soube 'dar a volta por cima' são interessantes ao nosso aprendizado, a obediência aos preceitos e costumes da tradição podem produzir resultados; enfim, o cumprimento das condições exigidas pelo "campo relacional" de pessoas a que pertencemos nos indica os caminhos mais úteis para se atingir a felicidade pretendida. Contudo, corre-se o risco de, no "cálculo de custo benefício" pertinente a nossa felicidade incorrermos no prejuízo dos outros, abrindo a prerrogativa para a imoralidade.

O fato de muitos se comportarem buscando o prazer e a satisfação imediata, mas se negarem a assumir a responsabilidade por algum erro, falta moral grave ou até pela prática de um delito, demonstra a forte tendência a relativização interesseira muito frequente em nossos dias. Kant desconfia da ação realizada num contexto utilitarista, pois quem age pode estar guiado por intenções que sempre visam 'o seu favor'; daí compreendemos a sua crítica aos 'eudemonistas' enquanto aqueles que se pretendem 'controlar as condições empíricas' originando o denominado "condicionado".

Sabendo dos limites do primeiro nível de decisões, Kant ascende ao segundo nível - o da moralidade, cujas decisões são tomadas a partir de princípios 'a priori' 
puros, remetendo a uma escala universal. É sempre bom relembrarmos a segunda fórmula do Imperativo categórico, fator incondicionado de fundamentação da moralidade:

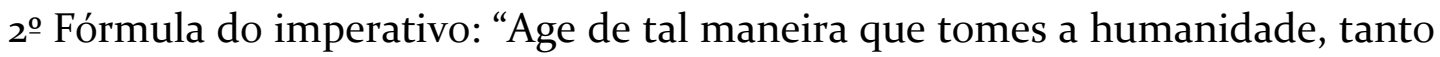
em tua pessoa, quanto na pessoa de qualquer outro, sempre ao mesmo tempo como fim, nunca meramente como meio" (KANT. 2009, p. 243-245)

Quando tratamos uma pessoa como objeto; ou seja, considerando-lhe o seu valor utilitário em função de alguma vantagem pessoal, usufruto prazeroso ao meu, ao teu e ao nosso favor, violando a segunda fórmula do Imperativo categórico, omitimos à pessoa o tratamento digno merecido, roubando-lhe o reconhecimento valorativo inestimável, cujo fim reside em si mesmo.

Quanto à última disposição: A disposição para a personalidade - refere-se ao respeito devido as pessoas, reconhecendo que são seres livres e agentes de moralidade tal como nós. Sobre esta disposição trataremos numa outra oportunidade. Encerramos com um trecho do próprio Kant (1992, p. 30):

As inclinações naturais, consideradas em si mesmas são boas, isto é, irrepreensíveis, e pretender extirpá-las não só é vão, mas também prejudicial e censurável; pelo contrário, há apenas que domá-las para que não se aniquilem umas às outras, mas possam ser levadas à consonância num todo chamado felicidade. Mas a razão que tal leva a cabo chama-se prudência. Só o moralmente contrário à lei é em si mau, absolutamente reprovável e deve ser exterminado, só a razão que tal ensina, e mais ainda quando o põe em obra, merece o nome de sabedoria.

\section{Referências}

BENTHAM, J. Uma introdução aos princípios da moral e da legislação. Trad. Luiz João Baraúna. Sistema de Lógica dedutiva e indutiva e outros textos. Trad. João Marcos Coelho, Pablo Mariconda. 2. ed. São Paulo: Abril Cultural, 1979 (Os Pensadores)

HOFFE, O. Immanuel Kant. Tradução: Valério Rohden et ali. São Paulo: Martins Fontes, 2005 .

KANT, I. A religião nos limites da simples razão. Tradução: Artur Morão. Lisboa: Edições 7o, 1992.

. Fundamentação da metafísica dos costumes; tradução: Guido Antônio de Almeida São Paulo: Discurso Editorial: Barcarolla, 2009 (Coleção philosophia)

. Crítica da razão prática. 2. ed. Tradução: Valério Rohden. São Paulo: Martins Fontes, 2008 (Clássicos)

. A metafísica dos costumes. Tradução: Edson Bini. 2. ed. Bauru, SP: Edipro, 2008 (Série Clássicos Edipro).

. Ideia de uma História universal do ponto de vista Cosmopolítico. Tradução: Jean Michel Muglioni e Yves Chateau. Lisboa - Portugal: Didática, 1999. 
FIGUEIREDO, R.

. Antropologia de um ponto de vista pragmático. Tradução: Clélia Aparecida Martins. São Paulo: Iluminuras, 2006.

Antropologia prática. 2. ed. Trad. Roberto Rodriguez Aramayo. Madrid - Espanha: Tecnos, 2007.

LIPOVETSKY, G. A sociedade pós-moralista: o crepúsculo do dever e a ética indolor dos novos tempos democráticos. Tradução: Armando Braio Ara. Barueri, SP: Manole, 2005.

Submissão: 10.10.2018 / Aceite: 30.11.2018 